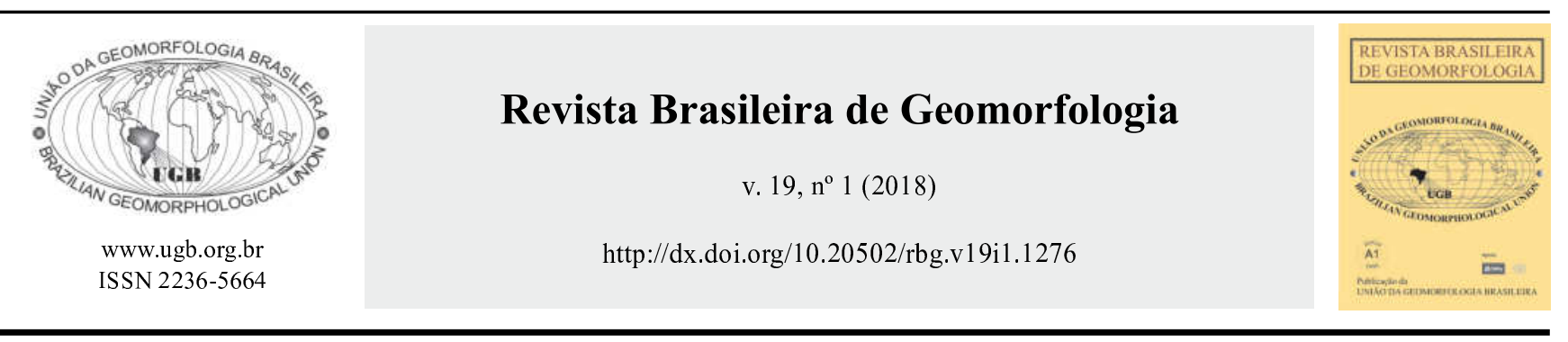

\title{
EVOLUÇÃO GEOMORFOLÓGICA DO SISTEMA LAGUNA - BARREIRA DE BILENE, COSTA DE MOÇAMBIQUE, ÁFRICA: PADRÕES CLIMÁTICOS E DINÂMICA SEDIMENTAR
}

\author{
GEOMORPHOLOGICAL EVOLUTION OF THE BARRIER-LAGOON \\ SYSTEM OF BILENE, MOZAMBIQUE COAST, AFRICA: CLIMATE \\ PATTERNS AND SEDIMENTARY DYNAMICS
}

\author{
Lucas Lavo António Jimo Miguel \\ Museu Nacional, Universidade Federal do Rio de Janeiro \\ Quinta da Boa Vista, Rio de Janeiro, Rio de Janeiro. CEP: 20.940-040. Brasil \\ Email: lucaslavomiguel@yahoo.com.br \\ João Wagner Alencar Castro \\ Museu Nacional, Universidade Federal do Rio de Janeiro \\ Quinta da Boa Vista, Rio de Janeiro, Rio de Janeiro. CEP: 20.940-040. Brasil \\ Email :jwacastro@gmail.com
}

\section{Informações sobre o Artigo \\ Recebido (Received): \\ 29/06/2017 \\ Aceito (Accepted): \\ $06 / 10 / 2017$}

\section{Palavras-chave:}

Dunas Transgressivas

Holocênicas; Nível do Mar;

Suprimento de Sedimentos;

Taxa de Movimentação;

Mobilidade de Sedimentos.

\section{Keywords:}

Holocene Transgressive Dunes; Sea Level; Sediment Supply; Dune Migration Rate; Sediment Mobility.

\section{Resumo:}

A dinâmica geomorfológica do sistema laguna - barreira da costa sul de Moçambique - África, reflete a interação entre o regime de marés, regime de ventos, precipitação pluviométrica e suprimento de sedimentos, ocorrida durante sucessivas variações do nível relativo do mar durante o Holoceno. Objetiva-se estudar os condicionantes geomorfológicos do sistema laguna-barreira de Bilene no sul de Moçambique, a partir dos padrões climáticos regionais e dinâmica sedimentar eólica. Analisou-se informações de precipitação pluviométrica de 52 anos, regime de ventos de 37 anos, registros de temperatura do atmosférica de 56 anos, mapa geológico na escala de 1:50.000, complementadas por um programa de monitoramento de movimentação de dunas transgressivas entre janeiro de 2016 e janeiro de 2017. Dados obtidos sugerem que as dunas costeiras associadas ao sistema laguna - barreira da área de estudo, são controladas principalmente pelo regime de vento, com taxa de migração de $23 \mathrm{~m} /$ ano. A taxa de transporte de sedimento eólico proveniente de SSW, S e SSE foi estimada em 1,4 kg/m/s.O índice de mobilidade dos sedimentos eólicos com ausência ou presença de vegetação, encontra-se na faixa entre 50 e 200 conforme índice pluviométrico regional de $1600 \mathrm{~mm} / \mathrm{ano}$, resultando em 70\% de cobertura vegetal sobre os campos de dunas do sistema laguna-barreira estudado. A atuação persistente desses fatores climáticos e sucessivas variações do nível relativo do mar durante o Holoceno combinadas ao alto suprimento de sedimentos, definiram o campo de dunas transgressivos associados a um sistema laguna-barreira de Bilene, costa sul de Moçambique. 


\begin{abstract}
:
The geomorphological dynamics of the barrier-lagoon system of southern Mozambique coast reflect the interaction between the tidal regime, wind regime, rainfall and sediment supply during successive variations of the relative sea level change during the Holocene. This research attempts to examine the geomorphological conditionings of the lagoon-barrier system of Bilene in southern Mozambique, based on regional climatic conditions and aeolian sedimentary dynamics. The methodological approach was based on the use of rainfall record of 52 years, 37 -years of winds record, 56-years of air temperature record, and 1: 50,000 geological map. Field data was obtained by a monitoring transgressive dune migration between January-2016 and January-2017. Results obtained suggest that the transgressive coastal dunes associated to the lagoon - barrier system are controlled by the persistent winds with a migration rate of $23 \mathrm{~m} /$ year. The sediment transport rate from the SSW, S and SSE was estimated to be1.4 kg/m/s. The mobility index of the aeolian sediments with absence or presence of vegetation was estimated between 50 and 200 linked to the regional rainfall of $1600 \mathrm{~mm} /$ year, resulting on $70 \%$ of vegetation cover on in the dunefields of the lagoon-barrier system studied. The persistent acting of these climatic factors and relative sea level changes during the Holocene combined with the high sediment supply, defined the transgressive dunefields associated to a barrier-lagoon system of Bilene, southern Mozambique coast.
\end{abstract}

\section{Introdução}

Os sistemas laguna-barreira armazenam informações importantes da ocorrência de registros geológicos de variações do nível do mar e condições climáticas pretéritas. Sua ocorrência em regiões costeiras é estabelecida pelas condições geológicas e oceanográficas, que definem características geomorfológicas, incluindo margens passivas com declividade suave e suprimento suficiente de sedimentos (Roy et al., 1994; Reinson, 1992; Hesp, 2013; Davis e Fitzgerald, 2004). Esses trabalhos verificaram que as feições geomorfológicas resultantes são mais comuns em ambientes costeiros dominados pelo regime de micro e mesomaré e nas regiões de latitudes médias a baixas. Sua evolução geomorfológica é bem notável ao longo de plataformas continentais com relevo relativamente suave. Perfis topográficos suaves dessas regiões permitem que sedimentos de tamanho de areia possam ser transportados para o interior da planície costeira, e atingidos por pistas de ventos moderados (Pye, 1983). Como resultado, a ação eólica condiciona um fluxo de sedimentos que origina feições morfológicas projetadas para o continente em condições lentas de variações do nível do mar ou neotectônicas.

A formação desses sistemas é decorrente do suprimento de sedimentos e do avanço progressivo/ regressivo do nível do mar sobre a planície costeira (Curray,1964; Dalrymple et al., 1992; Reinson, 1992; Boyd et al., 1992). Essas condições são mais observadas principalmente em sistemas onde a taxa de suprimento de sedimentos, excede a taxa de sobre-elevação do nível relativo do mar, como é o caso de Bilene, nas ilhas Inhaca e no arquipélago de Bazaruto em Moçambique (Armitage et al., 2006), e no litoral do Estado do Rio Grande do Sul, Brasil (Hesp et al., 2005; Dillenburg et al., 2006). A transgressão marinha cria espaços de acomodação de sedimentos e afogamento de antigos depósitos geológicos continentais, favorecendo a formação de barreiras e ou cordões litorâneos submersos. Durante a regressão, os sistemas barreiras/ cordões litorâneos e a planície de deflação formados são expostos às mudanças de condições climáticas e oceanográficas. O efeito conjugado desses fatores gera posteriormente campos de dunas-barreiras ou dunas transgressivas, controlados principalmente pelo regime de ventos, precipitação pluviométrica e suprimento de sedimentos (Castro et al., 2017; Martinho et al., 2008; Pye, 1983).

O suprimento significativo de sedimentos na costa provenientes da plataforma continental ou erosão das margens continentais, ocorre principalmente em condições de mar agitado caracterizado por ondas de tempestade e deriva litorânea forte. Essas condições oceanográficas são condicionantes principais do processo acentuado de erosão em escarpas compostas por sedimentos inconsolidados, disponibilizando grande volume de areia solta no ambiente costeiro. Souza et al. (2004) constataram ainda que nos ambientes dominados por enchentes ou altos índices fluviométricos (inundações), um volume significativo de sedimentos é transportado pela corrente fluvial do continente para as praias. Por outro lado, a atuação persistente de frentes 
de ondas em escala cronológica prolongada, acarreta um transporte de sedimentos da plataforma continental interna para o continente. A atuação desses processos ocasiona o engordamento da planície de deflação ou praia em direção ao mar, formando pós-praias extensas, separadas por dunas frontais. Na pós-praia, podem desenvolver-se feições geomorfológicas características resultantes de costas progradantes ocupadas por extensas planícies de deflação, cristas praiais ou cordões litorâneos (Souza et al., 2004; Fernandez, 2008).

Nesses sistemas, registra-se a presença de campos de dunas conforme orientação do vento dominante e deriva litorânea (Miot da Silva e Hesp, 2010). O processo de sedimentação eólica acarreta o desenvolvimento de campos de dunas transgressivas ativas e dunas semi-ativas ou fixas (Thomas e Wiggs, 2008; McKenna-Neuman et al., 1996; Argaman et al., 2006; Ashkenazy et al., 2012; Tsoar, 2013; Kinast et al., 2013). As dunas ativas ou semi-ativas ocorrem quando a velocidade do vento é superior a $6,0 \mathrm{~m} / \mathrm{s}$ (Fryberger, 1979), com precipitação anual considerável e cobertura da vegetação inferior a 30\% (Ash e Wasson, 1983). A remobilização e movimentação de dunas costeiras geralmente dependem de condições meteorológicas (Tsoar, 2005; Pye, 1983; Hesp, 2013; Kilibarda e Shillinglaw, 2014); Erosão costeira (Hesp, 2013; Aagard et al., 2007); Alterações relativas do nível do mar e suprimento de sedimentos (Pye, 1983; Ramsay, 1995; Argaman et al., 2006); Tamanho do grão e umidade da superfície da areia (Wiggs et al., 2004); Cobertura vegetal (Pye, 1993; Hesp, 2013); Declividade do perfil praia (Hesp et al., 2005); e atividades antrópicas.

A análise combinada desses fatores e suas relações de interdependência ainda é uma discussão em aberto (De Lecea et al., 2017; Gomes et al., 2016; Hesp, 2013; Armitage et al., 2006; Hobday, 1977; Cooper e Pilkey, 2002; Maud e Botha, 2000; Botha et al., 2003). Esses trabalhos admitem consensualmente que, variações do nível relativo do mar do Holoceno na costa sudeste africano ocorreram desde 7000 anos A.P. Suas oscilações cronológicas permitem a interpretação de vários sistemas costeiros resultantes, incluindo ilhas barreiras, dunas-barreiras, campos de dunas transgressivas associadas a sistemas laguna - barreiras.

Conceitos de campos de dunas e definição de modelos geológico-geomórficos são baseados em experiências européias e norte-americanas, e recentemente por australianas e brasileiras. Tais experiências indicam que diferenças de condições climáticas, geológicas e oceanográficas, geram sistemas eólicos diversos e sua formação é questionável. Baseando-se nessas constatações, nota-se uma falta pronunciada de pesquisas questionando a dinâmica dos campos eólicos transgressivos associados a sistemas barreiras ou cordões litorâneos na costa sul de Moçambique. Na tentativa de preencher essa lacuna, pretende-se através desta pesquisa examinar o controle de padrões climáticos e sedimentação costeira na formação de campos de dunas transgressivas associadas ao sistema laguna - barreira de Bilene, costa sul de Moçambique - África.

\section{Área de estudo}

O sistema laguna-barreira de Bilene, costa sul de Moçambique - África, caracteriza-se por cordões litorâneos paralelos a linha de costa, separados por corpos lacustres e lagunares (Figura 1). A exposição da planície costeira a variações do nível relativo do mar durante o Holoceno, favorecida pelo suprimento de sedimentos, o regime de maré e regime de ventos, permitiu o desenvolvimento morfológico de um campo de dunas transgressivas com alturas que podem atingir até $150 \mathrm{~m}$. Essas feições projetam-se em direção ao interior, promovendo muitas vezes, o assoreamento ou colmatação de corpos lacustres ou lagunares. $\mathrm{Na}$ retaguarda dos sistemas lagunares, desenvolveramse paleodunas, resultantes das variações de padrões paleoambientais, relacionadas à última transgressão holocênica. Ramsay (1995), Cooper e Pilkey (2002) e Botha et al. (2003) sugerem que o sistema de dunas transgressivas dessa região está entre os maiores da África e do mundo. Esse sistema barreira de dunas estende-se ao longo do litoral sudeste africano desde a cidade de Durban, África do Sul até na cidade da Beira na República de Moçambique.

O sistema laguna-barreira desse segmento de litoral caracteriza-se por cordões litorâneos arenosos alongados e paralelos à linha de costa. As feições geomorfológicas impostas pela dinâmica sedimentar,litorânea e eólica são constituídas por beachrocks, praias, paleodunas, dunas (barcanas, barcanóides, parabólicas e coppice) lagunas e sistemas lacustres. A exposição persistente do sistema laguna - barreira a eventos meteorológicos permite a formação de dunas móveis transgressivas ao sul e dunas vegetadas ao norte da área de estudo, 
incidindo quase que perpendicularmente a linha de costa atual. Armitage et al. (2006) estimaram que a formação do sistema de dunas transgressivas, iniciou no Pleistoceno e estendeu-se até o Holoceno. O grande volume de material depositado nas dunas é decorrente do suprimento de sedimentos, impulsionado pela pista de vento "fetch" favorecida por longos períodos sem chuva e variação maregráfica inferior a 4,0 m, iniciado por volta de 7000 anos A.P (Jaritz et al., 1977; Ramsay, 1995; Perry, 2004; Armitage et al., 2006).

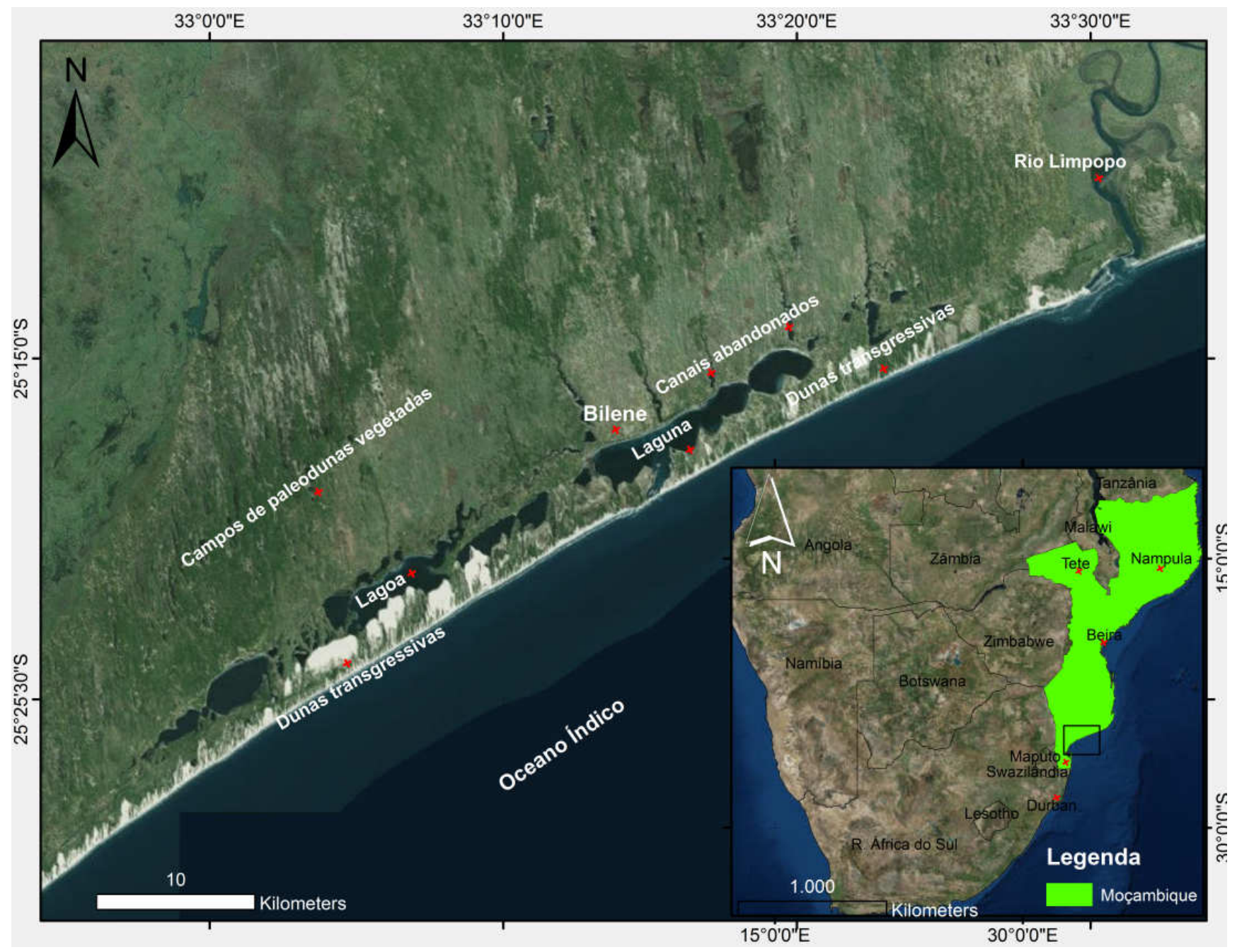

Figura 1 - Localização do sistema laguna-barreira de Bilene, costa sul de Moçambique.

O clima da região insere-se na faixa tropical úmida da escala de Köppen, influenciado por células tropicais anticiclônicas de baixa pressão e por frentes polares antárticas. Duas estações sazonais são bem distintas: o verão entre setembro e março e o inverno de abril a agosto. Segundo Været et al. (2011),a precipitação pluviométrica anual é de aproximadamente $1.300 \mathrm{~mm} / \mathrm{ano}$, com uma temperatura média mensal de $\sim 23^{\circ} \mathrm{C}$.O índice de evaporação anual média excede $1.100 \mathrm{~mm} /$ ano conforme informações entre 1954 e 2001. A precipitação máxima ocorre entre dezembro e março, quando a zona de convergência intertropical, atinge a região mais meridional da região sudeste de África(Moore et al., 2008).

Langa (2007) e Miguel et al. (2017) observaram que o regime médio mensal dos ventos varia entre 3,5 $\mathrm{m} / \mathrm{s}$ e $8,5 \mathrm{~m} / \mathrm{s}$ com frequências predominantes do NE, E, $\mathrm{SE}, \mathrm{S}$ e SW. Os ventos persistentes do SE, por vezes de até $22 \mathrm{~m} / \mathrm{s}$ entre julho e dezembro, são o principal fator na geração do clima de ondas regional com alturas de até $2,5 \mathrm{~m}$. A combinação do clima de ondas com o regime de meso-maré de até 4,0 $\mathrm{m}$,favorece correntes de deriva litorânea da região no sentido sul-norte de entre $60 \mathrm{~cm} / \mathrm{s} \mathrm{e}$ $80 \mathrm{~cm} / \mathrm{s}$ (Taskjelle et al., 2014). As correntes marinhas em alto mar caracterizam-se por deriva norte-sul, decorrente 
de giros periódicos anti-ciclónicos e ciclônicos (Halo et al., 2014). Esses giros influenciam sobremaneira o transporte de massas de água da corrente quente do canal de Moçambique, afetando o regime sazonal das estações anuais (Moore et al., 2008; Armitage et al.,2006).

\section{Materiais e métodos}

O estudo dos condicionantes geomorfológicos do sistema sedimentar laguna - barreira de Bilene, associado ao campo de dunas transgressivos, baseouse em análise de dados altimétricos, registros de velocidade e direção do vento (1960 - 2015), dados de precipitação pluviométrica (1960-2012) e temperatura atmosférica (1960-2012) complementados por técnicas de monitoramento de campo. A altimetria da região foi obtida através do Modelo Digital de Elevação - MDE, disponível no site do Projeto da Earth Explorer dos Estados Unidos, acessado em 2016 (Figura 2). Realizouse a compartimentação das unidades geomorfológicas através da utilização da curva de variação do nível de mar proposta por Ramsay (1995). Essa opção deve-se a uma melhor interpretação geocronológica e geomorfológica do sistema laguna-barreira, constituído por paleodunas interiores vegetadas, sistemas lacustres - lagunares e depósitos de dunas transgressivas holocênicas.

A análise do regime de ventos foi realizada através de registros históricos entre 1960-2015 de três estações meteorológicas, uma na província de Gaza em Xai-Xai, a segunda na província de Maputo e a terceira referente a estação regional meteorológica da NASA na coordenada

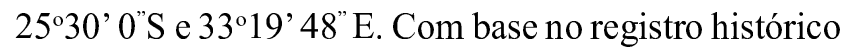
de dados da velocidade e direções do vento, selecionou-se velocidades superiores a $6,0 \mathrm{~m} / \mathrm{s}$, limite estabelecido por Castro (2001) e Tsoar $(2005,2013)$. Tal limite permite o início do transporte de areia eólica solta (Liu et al., 2005) que pode formar feições geomorfológicas, incluindo dunas transgressivas. Classificou-se as orientações do vento em N, NNW, NW, WNW, W, WSW, SW, SSW, S, SE, ESE, E, NNE e NE visando determinar a taxa de transporte de areia Q (Q em kg/m/s), conforme modelo proposto por Lettau e Lettau (1978).

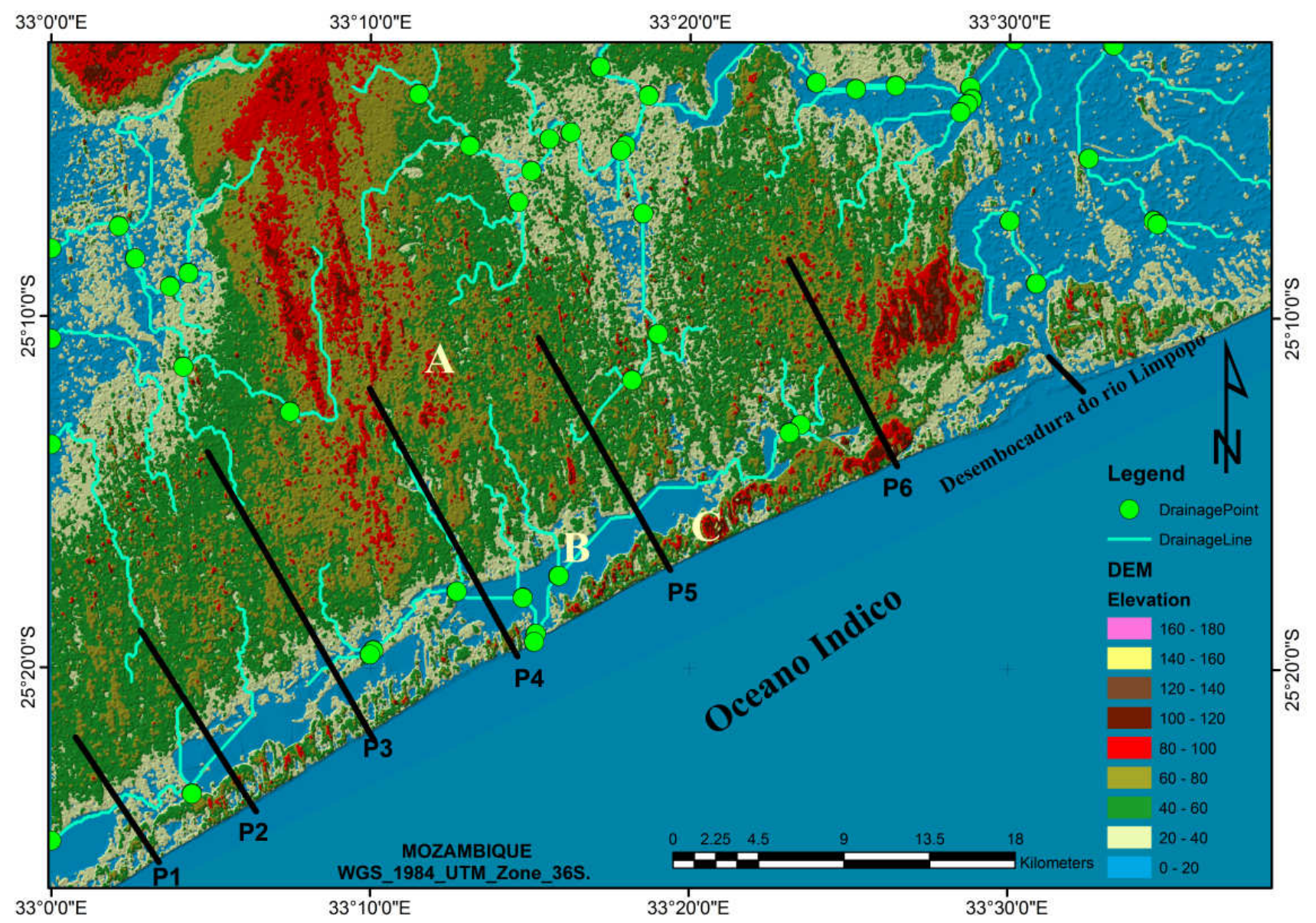

Figura 2 - Seç̧ões transversais do sistema laguna-barreira: P1, P2, P3, P4, P5 e P6. (A) Paleodunas internas vegetadas; (B)Sistemas lacustres - lagunares; (C) Depósitos de campos de dunas transgressivos holocênicos. 


$$
Q=C_{b} \sqrt{\frac{d}{D}} \frac{\rho}{g}\left(w-w_{r e f}\right) w^{2}
$$

onde:

$\mathrm{C}_{\mathrm{b}}$ é constante $=6,7$ (Lettau e Lettau, 1978);

d: Tamanho médio do grão do sistema de dunas estudado $=0,375 \mathrm{~mm}$;

D: Tamanho de grão de referência $=0,25 \mathrm{~mm}$;

q: Densidade do ar $=1,22 \mathrm{~kg} / \mathrm{m}^{3}$;

$\mathrm{g}$ : Aceleração de gravidade $=9,81 \mathrm{~m} / \mathrm{s}^{2}$;

W: Velocidade de vento registrada por hora na estação $25,50^{\circ} \mathrm{S}-33,33 \mathrm{E}$;

$\mathrm{W}_{\text {ref }}$ : Velocidade limiar de fricção $=6,0 \mathrm{~m} / \mathrm{s}$.

O potencial de deriva - DP foi determinado através da equação proposta por Fryberger's (1979):

$$
D P=w^{2}\left(w-w_{r e f}\right) t
$$

onde:

$\mathrm{W}$ : Velocidade superior a $6,0 \mathrm{~m} / \mathrm{s}$;

$\mathrm{W}_{\text {ref }}: 6,0 \mathrm{~m} / \mathrm{s}$;

t: Incremento de tempo em relação às medidas anuais de registro de dados de vento em porcentagem.

O índice de mobilidade da areia - M (adimensional) foi calculado através da equação proposta por Lancaster (1988):

$$
M=W \frac{E}{P}
$$

onde:

W: Porcentagem anual de vento superior a $6,0 \mathrm{~m} / \mathrm{s}$ entre 1979 a 2016;

P: Média anual de precipitação entre 1960 e 2012;

A média anual de evapotranspiração (E) é de $1100 \mathrm{~mm} /$ ano (Været et al., 2011).

O monitoramento direto no terreno do sistema sedimentar laguna - barreira de Bilene - Moçambique foi realizado através do acompanhamento de movimentação de uma duna do tipo parabólica, situada sobre o primeiro cordão litorâneo na coordenada $25^{\circ} 23^{\prime} 60^{\prime \prime} \mathrm{S}$ e $33^{\circ}$ 8' 24" E. Utilizou-se como referência uma estaca de madeira. Essa metodologia, proposta por Castro (2001) apesar de simples, pode ter resultados significativos em dunas transgressivas móveis, onde os processos de migração de feições eólicas têm atingido vastas áreas, especificamente no sistema sedimentar laguna - barreira de Bilene.

Por ocasião da primeira campanha de monitoramento, a duna escolhida para controle apresentava os seguintes parâmetros geomorfológicos: Formaparabólica; Largura-70 m; Altura média-100 m;Sentido de migração- NW e Mergulho da face de deslizamento $-24^{\circ}$. A estaca de madeira foi orientada perpendicularmente à crista da duna,disposta a direção dominante de movimentação. O monitoramento envolveu um período de tempo de um ano entre janeiro de 2016 e fevereiro de 2017.

Realizou-se uma análise histórica de dados de precipitação pluviométrica entre 1960 e 2012 nas estações meteorológicas de Xai-Xai e Maputo. Os registros foram analisados estatisticamente,visando obter as médias mensais e anuais. As séries foram agrupadas em períodos de 10 anos, perfazendo um total de 52 anos. O registro histórico de dados de temperatura entre 1960 e 2012 foi coletado através das estações meteorológicas utilizadas. Esses dados foram analisados de forma semelhante aos conjuntos de dados de precipitação. Os dados foram separados em temperaturas diárias máximas e mínimas. Os picos foram comparados à ocorrência dos fenômenos $E l$ Niño e La Niña (Humphries et al., 2016) seguindo a metodologia proposta por Castro (2001).

\section{Resultados}

Foram obtidos seis perfis altimétricos perpendiculares à linha de costa. Verificou-se em todos os perfis analisados cinco compartimentos geomorfológicos bem distintos, representados por: paleodunas interiores - cobertas pela vegetação com altitudes entre 1,0 e 5,0m; sistema lacustre - lagunar quase que na mesma posição do nível do mar atual; dunas transgressivas holocênicas (fixas e móveis) -com altitudes de $2 \mathrm{~m}$ a $150 \mathrm{~m}$; planície de deflação e ambiente de praia atual (Figura 3 ). 

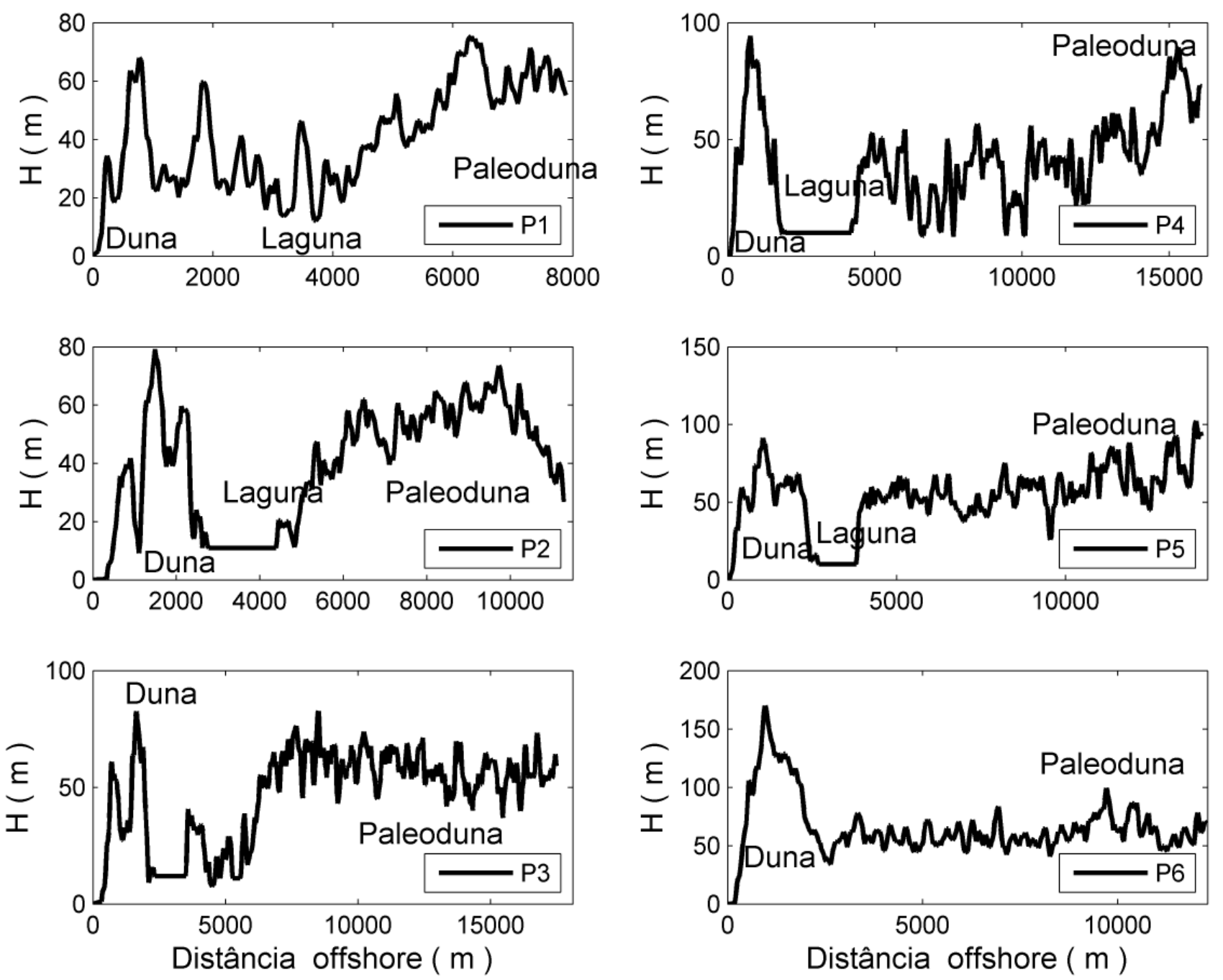

Figura 3 - Perfis topográficos do sistema laguna-barreira de Bilene, Moçambique.

Resultados obtidos do regime de ventos correspondente ao período entre 1979 e 2016 indicaram uma velocidade média mensal superior a $6,0 \mathrm{~m} / \mathrm{s}$. Enquanto a média de dados analisado em décadas exibiu variações entre $5,0 \mathrm{~m} / \mathrm{s}$ e $8,5 \mathrm{~m} / \mathrm{s}$ proveniente dos quadrantes N, NNW, NW, WNW, W, WSW, SW, SSW, S, SSE, SE, ESE, E, NNE, NE e SE. O intervalo da velocidade exibida indica a atividade eólica persistente proveniente de $\mathrm{S}=14,3 \%, \mathrm{SSE}=21 \%, \mathrm{SE}=13 \%, \mathrm{E}=$ $7,34 \%, \mathrm{ESE}=7,2 \%, \mathrm{NNE}=6,9 \%$ e $\mathrm{N}=10 \%$.

A taxa de transporte de sedimento eólico conforme equação proposta por Lettau e Lettau (1978) foi estimada para todos os quadrantes em $1,38 \mathrm{~kg} / \mathrm{m} / \mathrm{s}$. A grande contribuição foi proveniente dos quadrantes $\mathrm{SW}=0,13$ $\mathrm{kg} / \mathrm{m} / \mathrm{s}, \mathrm{SSW}=0,28 \mathrm{~kg} / \mathrm{m} / \mathrm{s}, \mathrm{S}=0,27 \mathrm{~kg} / \mathrm{m} / \mathrm{s}$ e SSE $=$ $0,17 \mathrm{~kg} / \mathrm{m} / \mathrm{s}$. A taxa de transporte eólico anual variou significativamente de 1980 a 2015 entre $130 \mathrm{~kg} / \mathrm{m} /$ anoem
1993 e $501 \mathrm{~kg} / \mathrm{m} /$ anoem 2003 (Tabela 1). A taxa de menor transporte foi caracterizada por valores baixo potencial de deriva (DP) de 175 v.u, elevada precipitação de 772 $\mathrm{mm} /$ ano, índice baixo de mobilidade de 74. Enquanto a taxa de maior transporte foi caracterizada com maior $\mathrm{DP}=1193 \mathrm{v} . \mathrm{u}$, baixa precipitação $=354 \mathrm{~mm} /$ ano e alto índice de mobilidade eólico $=318$.

O potencial de deriva determinado através da equação proposta por Fryberger's (1979) apresentou uma média de 382 v.u (Tabela 1). Os meses que apresentaram maior potencial de deriva entre $1979 \mathrm{e}$ 2016 foram: junho $=1085 \mathrm{v} . \mathrm{u}$, julho $=1573 \mathrm{v}$.u, agosto $=3030 \mathrm{v} . \mathrm{u}$, setembro $=2832 \mathrm{v} . \mathrm{u}$ e novembro $=2011 \mathrm{v}$.u. E o índice de mobilidade da areia eólica-M através da equação proposta por Lancaster (1988) foi estimado em 50 a 200 entre 1979 e 2016 (Tabela 1). O menor índice foi registrado em 2000 com precipitação $=1601 \mathrm{~mm} /$ 
Miguel L. L. A. J. \& Castro J. W. A.

ano e o maior índice foi registrado em 2003 com 187 e precipitação $=354$. Enquanto que as determinações diretas no terreno de movimentação de uma duna parabólica sobre o primeiro cordão litorâneo do sistema laguna - barreira foi de $23 \mathrm{~m} / \mathrm{ano}$.

A análise da precipitação $(\mathrm{P})$ indicou média de $71 \mathrm{~mm} /$ mês entre 1969 e 1979, $63 \mathrm{~mm} /$ mês de 1980 a 1989, 65,4 mm/mês de 1990 a 1999 e 65 mm/mês de
2000 a 2012. Resultados obtidos através de análises de temperaturas e índices pluviométricos sugerem ocorrência dos episódios El Niño e Lã Niña com intensidades relativamente baixas ou moderadas. Os efeitos de El Niño foram observados em 1982, 1983, 1991, 1992, 2004, 2005 e 2006, enquanto os indicadores de Lã Nina foram registrados em 1975, 1981, 1984, 1994, 1995, 2000, 2007, 2009 e 2011(Tabela 1).

Tabela 1: Resultados de Potencial de Deriva; Precipitação (mm/ano), Índice de mobilidade eólica (M) e Taxa de transporte $(Q=\mathrm{kg} / \mathrm{m} / \mathrm{s})$

\begin{tabular}{|c|c|c|c|c|c|c|c|c|c|c|c|c|c|c|c|c|}
\hline \begin{tabular}{|c|} 
Anosi \\
DP
\end{tabular} & Janeiro & Fevereiro & Março & Abril & Maio & Junho & Julho & Agosto & Setembro & Outubro & Novembro & Dezembro & DP (v.u) & $\begin{array}{c}\text { P.(mm / } \\
\text { ano) }\end{array}$ & $M=w(E T P / P)$ & $\mathrm{Q}(\mathrm{kg} / \mathrm{m} / \mathrm{ano})$ \\
\hline 1980 & 112 & - & - & - & - & - & - & - & - & - & - & - & 112 & 667 & 88 & 146 \\
\hline 1981 & - & - & - & - & - & - & - & 124 & 306 & 98 & - & - & 529 & 1182 * & 53 & 261 \\
\hline 1982 & - & 40 & - & - & - & - & - & - & - & - & 101 & 54 & 195 & 450 ** & 135 & 187 \\
\hline 1983 & - & 216 & - & - & - & - & 90 & 44 & 131 & 51 & - & - & 532 & 652 ** & 94 & 227 \\
\hline 1984 & 190 & 157 & - & - & - & - & - & - & - & - & - & - & 347 & 1261 * & 50 & 220 \\
\hline 1985 & - & - & - & - & - & - & - & 10 & 159 & 63 & 25 & - & 257 & 959 & 62 & 136 \\
\hline 1986 & - & - & - & - & - & - & - & - & - & - & 60 & 31 & 91 & 485 & 123 & 146 \\
\hline 1987 & - & - & - & - & - & 52 & 109 & - & - & - & 39 & - & 200 & 557 & 97 & 151 \\
\hline 1988 & - & - & - & - & - & - & - & - & - & - & - & - & - & 612 & 96 & 254 \\
\hline 1989 & - & - & - & 25 & - & - & 21 & - & - & - & - & - & 45 & 697 & 93 & 352 \\
\hline 1990 & - & - & - & - & - & - & - & - & 74 & 150 & 184 & 67 & 474 & 881 & 63 & 212 \\
\hline 1991 & 49 & 116 & - & - & - & - & & 154 & - & - & - & - & 319 & $587^{* *}$ & 102 & 274 \\
\hline 1992 & - & - & - & - & - & - & 17 & 59 & 141 & - & - & - & 217 & $542^{* *}$ & 108 & 261 \\
\hline 1993 & - & - & - & - & - & - & - & - & 10 & - & 149 & 16 & 175 & 772 & 74 & 132 \\
\hline 1994 & - & - & - & 3 & - & 50 & 37 & - & - & - & - & - & 89 & 458 & 134 & 269 \\
\hline 1995 & - & - & 6 & 48 & - & 4 & 68 & - & - & 167 & - & 29 & 323 & $641^{*}$ & 99 & 270 \\
\hline 1996 & - & - & 27 & - & - & - & 93 & 239 & 149 & 147 & 66 & - & 722 & 894 & 73 & 322 \\
\hline 1997 & - & - & - & - & - & - & 7 & & 58 & 200 & 123 & 23 & 411 & 1010 & 64 & 324 \\
\hline 1998 & - & - & - & - & - & - & - & 67 & - & - & - & 39 & 106 & 965 & 62 & 329 \\
\hline 1999 & 21 & - & - & - & - & - & - & 18 & 261 & 107 & 21 & - & 429 & 1105 & 52 & 174 \\
\hline 2000 & 100 & 12 & - & - & - & - & - & - & - & 116 & 201 & 15 & 443 & 1601 * & 37 & 386 \\
\hline 2001 & 197 & 90 & - & - & - & - & 138 & - & 267 & - & - & - & 691 & 846 & 71 & 416 \\
\hline 2002 & - & - & 4 & - & - & - & 7 & - & 57 & 290 & - & - & 358 & 386 & 161 & 348 \\
\hline 2003 & 24 & - & - & - & - & 90 & - & 260 & 238 & 282 & 119 & 179 & 1193 & 354 & 187 & 501 \\
\hline 2004 & 64 & - & - & - & - & - & 86 & 1 & - & 161 & - & 12 & 324 & $860^{* *}$ & 67 & 260 \\
\hline 2005 & - & - & - & 29 & - & - & 3 & 117 & 115 & 208 & 91 & 187 & 749 & $535^{* *}$ & 118 & 318 \\
\hline 2006 & - & - & - & - & - & - & 173 & - & 12 & 50 & 113 & - & 348 & $916^{* *}$ & 70 & 229 \\
\hline 2007 & 38 & 5 & 40 & - & - & & 25 & 227 & 64 & 161 & 140 & - & 701 & $805^{*}$ & 68 & 331 \\
\hline 2008 & - & 26 & - & 18 & - & - & - & - & - & - & - & - & 44 & 633 & 98 & 410 \\
\hline 2009 & - & 1 & 6 & 12 & - & 7 & & 32 & 163 & - & - & - & 221 & $739 *$ & 80 & 231 \\
\hline 2010 & - & - & - & - & - & - & - & - & 178 & 197 & 148 & 46 & 568 & 966 & 63 & 267 \\
\hline 2011 & - & - & - & 13 & 5 & - & 210 & 91 & - & 53 & - & - & 371 & $768^{*}$ & 81 & 300 \\
\hline 2012 & 90 & - & 29 & 3 & - & - & 3 & 65 & 299 & - & - & - & 489 & 578 & 107 & 314 \\
\hline 2013 & - & - & 13 & - & - & - & - & 65 & 162 & 120 & 79 & - & 438 & - & 78 & 204 \\
\hline 2014 & - & - & & 18 & - & - & - & - & 61 & 160 & 112 & & 351 & - & 61 & 176 \\
\hline 2015 & - & - & - & - & - & - & - & - & 126 & 51 & 238 & 80 & 496 & - & 66 & 207 \\
\hline 2016 & 7 & 55 & - & - & - & - & - & - & - & - & - & - & $?$ & - & 94 & - \\
\hline \multirow[t]{2}{*}{ Total } & 792 & 718 & 125 & 169 & 5 & 203 & 1085 & \begin{tabular}{|l|}
1573 \\
\end{tabular} & 3030 & 2832 & 2011 & 779 & & & & \\
\hline & & & & & & & & & ** & $\begin{array}{c}\text { El } \\
\text { Niño }\end{array}$ & * & \multicolumn{5}{|l|}{ Lã Niña } \\
\hline
\end{tabular}




\section{Discussão}

A dinâmica sedimentar do sistema laguna - barreira de Bilene em Moçambique é resultante do transporte de sedimento litorâneo e da praia, controlado pelo índice pluviométrico e pelo regime de marés, menor ou igual a 4,0 m. O transporte sedimentar é condicionado por correntes de deriva litorâneo sul-norte de até $80 \mathrm{~cm} / \mathrm{s}$ (Taskjelleet al., 2014), transportando sedimentos da plataforma interna para a planície de marés. A pista de ventos de até $22 \mathrm{~m} / \mathrm{s}$ durante a estação seca transporta sedimentos expostos na praia formando dunas. Esses processos foram impulsionados ao longo do tempo pelas variações do nível do mar durante o Holoceno, gerando conforme Roy et al. (1994), uma configuração morfológica característica de costa dominada por ondas. Essa hipótese é decorrente da apresentação de uma baixa declividade do perfil da plataforma interna, energia da onda moderada, regime de mesomarés, disponibilidade de sedimentos, existência de espaços de acomodação e ocorrência de taxas regressivas, transgressivas e estacionárias do nível do relativo do mar durante o Holoceno. Essas características possibilitaram a formação de um sistema barreira alongado, paralelo ao litoral, albergando um sistema lacustre-lagunar ou pântanos.

Do ponto de vista geomorfológico, a hipótese apresentada por Boyd et al. (1992) apesar de simples é efetiva na interpretação da formação atual do sistema laguna-barreira de Bilene, sul de Moçambique. A sua formação e evolução geológica, acarretou o desenvolvimento de paleodunas interiores, dunas transgressivas (parabólicas, coppice e barcanas) e ambientes lacustre-lagunares, condicionados pelas mudanças relativas do nível do mar e pelo suprimento de sedimentos. As mudanças relativas do nível do mar da região foram previamente identificadas por Ramsay (1995) através de datações radio carbono $14\left({ }^{14} \mathrm{C}\right.$ ) (Figura 4). O suprimento de sedimentos e o mecanismo de transporte de sedimento e processos deposicionais foram discutidos por Norstrom et al. (2011), Botha e Porat (2000), Botha et al. (2003), Maud e Botha (2000), Armitage et al. (2006), Hobday (1977), Gomes et al. (2017) e Cooper e Pilkey (2002). Esses trabalhos admitem por unanimidade que a fonte de sedimentos é a plataforma continental complementada pela sedimentação continental.

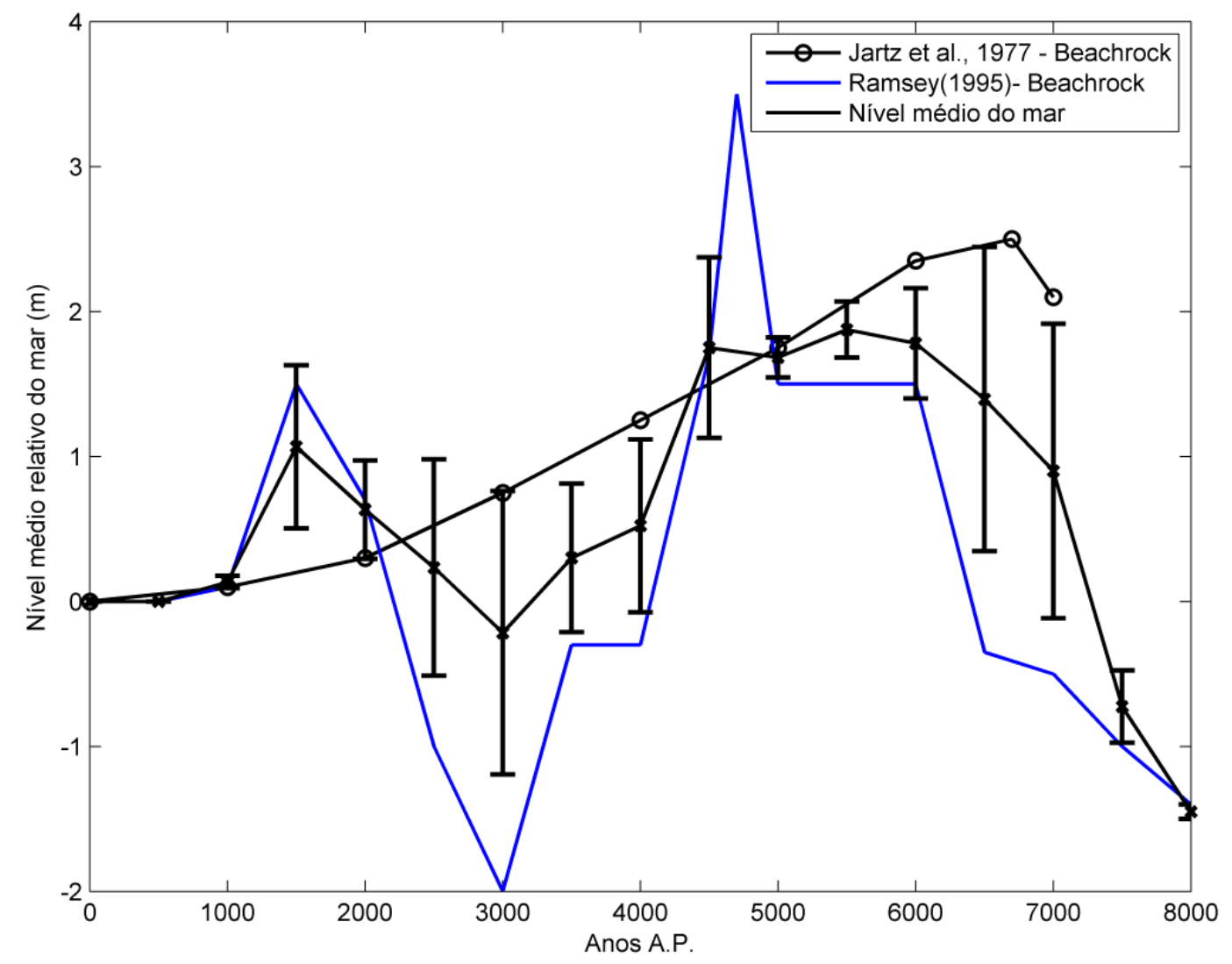

Figura 4 - Curva de variação do nível relativo do mar da costa sudeste de África durante 8,000 anos A.P. 
Apesar da discussão sobre variações do nível relativo do mar na área de estudo, ocorridas entre 2,500 anos A. P e 1,500 anos A. P por Ramsay e Cooper (2002) e Armitage et al. (2006) gerar incertezas, sugere-se que a sobre-elevação marinha holocênica foi a principal responsável pela formação da duna-barreira estudada, atualmente ocupada por um campo de dunas transgressivos iniciados durante o mesmo período. As projeções dessas feições para o interior, devemse a direção predominante dos ventos de orientação sudeste - noroeste. A queda subsequente do nível do mar propiciou a formação de praias amplas submetidas a regime de meso-maré e desembocaduras de marés (Figura 1). Trabalho realizado por Gomes et al. (2017) confirma esse mesmo tipo de registro geológico na região do estuário da Santa Lucia na costa leste da República da África do Sul.

Conforme Figura 1, a configuração morfológica apresenta indícios dos efeitos decorrentes de mudanças relativas do nível do mar nesse segmento de litoral. Por exemplo, pode inferir-se que as paleodunas transgressivas de retaguarda foram desenvolvidas entre 7.000 anos A.P e 5.000 anos A.P com nível máximo atingindo até cerca de 3,0 $\mathrm{m}$ acima do atual. Esse processo transgressivo foi identificado por Gomes et al. (2017), Maud e Botha (2000), Ramsay (1995) e Armitage et al. (2006) na mesma região. A evolução geomorfológica das paleodunas interiores é resultante de tendências do nível do mar, ao suprimento de sedimentos, existência de espaço de acomodação e aos processos de sedimentação. As paleodunas interiores do sistema laguna-barreira de Bilene, sugerem a mesma série de aumentos escalonados do nível do mar durante a última glaciação identificados por De Lecea et al. (2017). Acredita-se que tais aumentos favoreceram ciclos intercalados com ravinamento de maré e condições climáticas persistentes nas barreiras interiores. Sua evolução dependeu da progradação da margem continental para a formação de dunas antigas (paleodunas de retaguarda) na condição de nível do mar alto (De Lecea et al., 2017).

A compartimentação geomorfológica das dunas transgressivas contemporâneas sugere uma formação similar às paleodunas nas condições alternadas de nível estacionário e transgressivo do mar, as mesmas que formaram o complexo estuarino de Santa Lúcia a $400 \mathrm{~km}$ ao sul da área de estudo (Gomes et al., 2017; Benallack et al., 2016). A evolução holocênica do sistema laguna - barreira de Bilene sugere forte influência marinha com períodos de aumento rápido do nível do mar que propiciou o afogamento das feições morfológicas frontais. $\mathrm{O}$ afogamento foi alternando com períodos de influência de drenagens, favorecendo a progradação marginal durante possíveis períodos de estabilidade do nível do mar ou aumento lento (De Lecea et al., 2017). Esses períodos favoreceram a formação de eolianitos e rochas de praia, sugerindo uma queda ligeira do nível do mar a partir do optimum climático holocênico quando a drenagem marginal progrediu episodicamente durante inundações. A fase final de regressão marinha resultou na deposição que conduziu à situação contemporânea da barreira arenosa, caracterizada por dunas progradantes e sistemas lacustres.

A queda o nível do mar de 4,0 m para $0,0 \mathrm{~m}$ entre 4.500 anos A.P e 3.000 anos A.P (Ramsay, 1995; De Lecea et al., 2017; Gomes et al., 2017), formou um sistema de lagoas paralelo ao litoral que estendemse de Quissico na Província de Inhambane até ao complexo sistema estuarino da Santa Lucia na África do Sul. Esses sistemas são geralmente constituídos por areia cimentada, matéria orgânica negra, depósitos de conchas, restos de matéria orgânica decomposta. A matéria orgânica identificada é resultado da mudança de condições paleoambientais pretéritas que ocorreram durante a queda do nível do mar (Botha et al., 2000).

Os registros sedimentares encontrados no sistema laguna-barreira de Bilene indicaram alterações geomorfológicas em condições de alta energia, contrário de alterações geomorfológicas do complexo estuário de Santa Lucia na África do sul por Benallack et al. (2016) que indicaram condições de baixa energia marinha. As condições de alta energia associadas ao alto suprimento de sedimentos e baixa declividade do perfil da praia formaram uma barreira (cordão arenoso) paralela à costa com dunas de até $150 \mathrm{~m}$ e sistemas lacustre - lagunares em Bilene, sul de Moçambique. As condições de baixa energia favoreceram o crescimento da barreira e a interrupção de canais de comunicação com o oceano em 6.200 anos A.P para a formação do estuário de Santa Lucia na África do Sul.

A barreira paralela a costa formada foi modificada por incursões periódicas relacionadas as variações do nível relativo do mar com alturas de regressões ou estacionários incoerentes. Por outro lado, Gomes et al. (2017) e De Lecea et al. (2017) sugeriram que as invasões marinhas periódicas e por vezes episódicas da região, podem estar associadas a regime de fortes 
tempestades que persistentemente atuaram até pelo menos $\sim 1200$ anos A.P. Esse período teria favorecida o suprimento de sedimentos que formou a presente barreira e posterior transporte eólico que formou dunas transgressivas de até $150 \mathrm{~m}$, os sistemas lacustres lagunares e planícies de deflação (Figura 5).

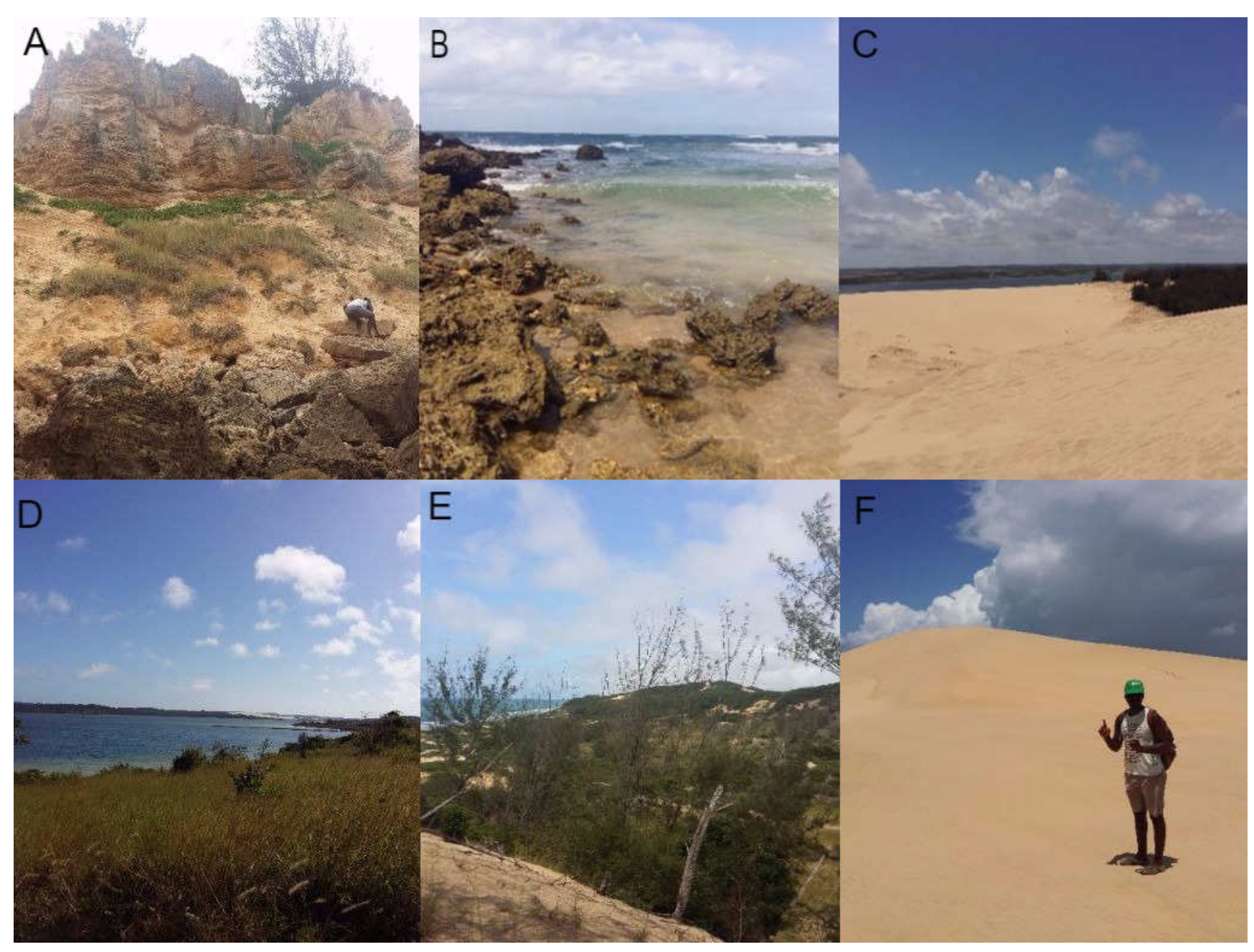

Figura 5 - Depósitos sedimentares do sistema laguna - barreira de Bilene no sul de Moçambique. (A) Depósitos de eolianitos; (B) Rochas de praia (Beachrocks); (C) Sistema lacustre em processo de assoreamento por duna parabólica transgressiva; (D) Sistema lacustre com vegetação; (E) Duna parabólicas transgressivas de 100 m de altura; (F)- Duna transgressiva (barcana móvel).

A evolução geomorfológica do sistema laguna - barreira de Bilene foi extensivamente remodelada na segunda fase pela sedimentação eólica. Resultados obtidos sobre o regime de ventos da área de estudo apontam para a formação de dunas transgressivas que se projetam para o interior com orientação SE - NW. A análise temporal da variabilidade do vento entre 1979 e 2016 aponta para ventos com alta capacidade de transporte de sedimentos eólicos durante todo ano. Esse transporte não depende apenas da ação eólica mas também do índice de mobilidade de sedimentos eólicos. Por sua vez, o índice de mobilidade de sedimentos depende do índice pluviométrico, evaporação, umidade do ar, nível de lençol freático, fonte de sedimentos, temperatura atmosférica, efeitos episódicos - ENSO e cobertura da vegetação (Yizhaq et al., 2008; Castro, 2001). Apesar do envolvimento desses fatores na dinâmica sedimentar, ficou evidente que o regime de ventos e índices pluviométricos destacaram-se de forma significativa no processo continuo de progradação transgressiva das dunas.

As taxas de transporte e migração das dunas são confirmadas pela formação de campos de dunas transgressivos que prograda para o continente soterrando vegetação e assoreando intensivamente lagos, lagunas e lagoas locais, e desligamento pronunciado de vários 
canais de comunicação com o oceano. Essas mesmas condições foram identificadas por (Hesp, 2013; Castro, 2005). O processo de assoreamento e soterramento intenso está bem explicado pelo índice de mobilidade das dunas estimado entre 50 e 200 , que corresponde a dunas semi-ativas no sul da África previamente identificadas por Lancaster e Lancaster (1988). Por outro lado, o índice de mobilidade correlacionou exponencialmente bem com a precipitação com índice de significância de $\left(\mathrm{r}^{2}\right)=0,91$, demonstrando sua interdependência na sedimentação eólica.

O resultado da taxa de movimentação médio de $23 \mathrm{~m} /$ ano, é superior a $11 \mathrm{~m} /$ ano encontrados por Castro (2001) no Brasil, 16,0 m por Sauermann et al. (2003) no Estado de Ceará (Brasil), e por Levin (2010) na costa da Austrália. Essa progradação de dunas parabólicas transgressivas corrobora os valores do índice de mobilidade que integra as dunas do sistema lagunabarreira de Bilene na faixa de dunas semi-ativas e fixo - ativas do modelo proposto por Yizhaq et al. (2008).

Com base na classificação de potencial de deriva proposta por Fryberger (1979), o sistema eólico estudado, enquadra-se na faixa de deriva intermediária. Nessa escala o vento é forte indicador de aceleração do processo de progradação das dunas transgressivas em ambientes transicionais. A progradação é interpretada com efetividade no modelo proposto por Yizhaq et al. (2008). Com base nesse modelo, as dunas transgressivas do sul de Moçambique, integram-se perfeitamente nas faixas fixo - ativas e fixas (Figura 6). O grau de eficácia do modelo foi confirmado com as observações de campo, com grande parte de dunas fixo - ativas, que estendem-se até Quissico na Província de Inhambane, Moçambique.

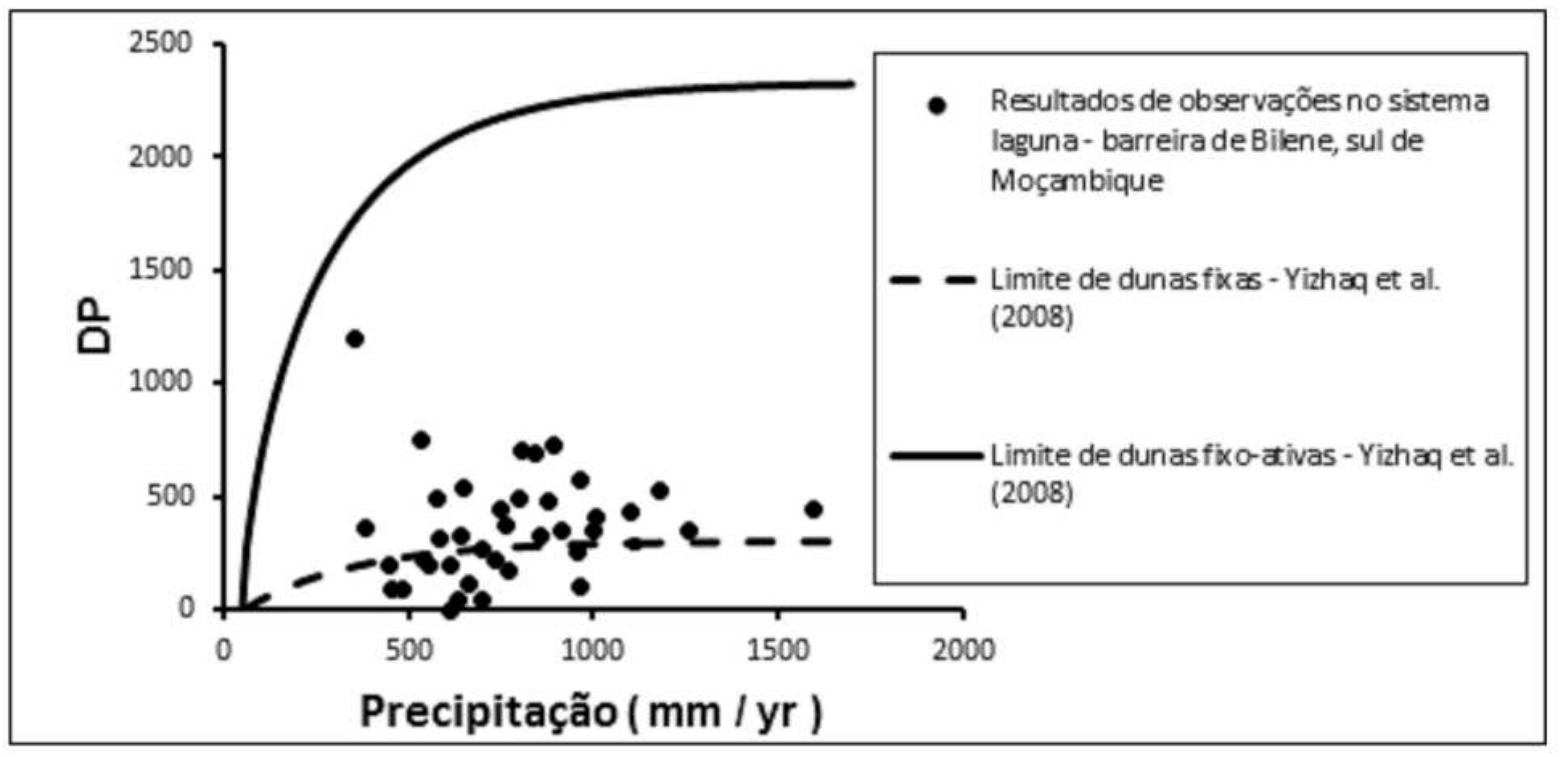

Figura 6 - Integração das dunas transgressivas da costa Sul de Moçambique no modelo numérico de Yizhaq et al. (2008).

A precipitação média anual de $850 \mathrm{~mm} /$ ano é relativamente significativa. Estimulou uma considerável colonização da vegetação acima de $30 \%$, estabilizando as paleodunas de retaguarda e dunas contemporâneas. Por outro lado, acredita-se que possíveis esvaziamentos dos reservatórios de água provocados pela evaporação e consequente diminuição de lençóis freáticos do sistema, condicionam a aceleração de atividade eólica em períodos secos.

Observou-se que a precipitação desacelerou a mobilidade das dunas nos períodos chuvosos pelo aumento significativo da umidade da superfície das dunas. O efeito pluviométrico negativo é firmado pela baixa velocidade média mensal do vento inferior a $13 \mathrm{~m} / \mathrm{s}$, limite mínimo proposto por Anthonsen et al. (1995). Essas condições favorecem a mobilidade dos sedimentos em superfícies úmidas. Efeitos típicos foram relatados em outros sistemas transicionais costeiros com características similares (Pye, 1993; Lancaster, 2013; Yizhaq et al., 2008; Yizhaq et al., 2013; Tsoar, 2013; Silva et al., 2008; Castro, 2001 e 2005). Esses trabalhos destacam o papel da precipitação pluviométrica como uma variável principal que induz a desaceleração de transporte de sedimentos em regimes sazonais. 
A ocorrência episódica de fenômenos ENSO, previamente relatados por Kumar et al. (2014) no sudeste da África, Humphrieset al. (2016) no estuário de Santa Lúcia na África do Sul, pode ter contribuído na aceleração do transporte de sedimentos e posterior progradação intensa das dunas (Castro, 2001;Ash e Wasson, 1983; Yizhaq et al., 2013; Tsoar et al., 2013). Vale destacar que as anomalias ENSO são relevantes para o transporte de sedimentos e progradação de campos de dunas em áreas onde podem causar secas intensas. De fato, as secas são teleconectadas por fortes anomalias ENSO e podem impulsionar fortemente a migração de dunas, como destaca Maia et al. (2005) no Estado do Ceará - Brasil. Por outro lado, Hastenrath (2006) discute que os eventos ENSO não só intensificam períodos de seca, mas também podem aumentar períodos de precipitação pluviométrica. Neste caso, qualquer relação de ENSO com a seca é incerta e tem um baixo nível estatístico de significância (Gasques e Magalhes, 1987). Nesta perspectiva, um único efeito ENSO não explica a migração de dunas em Moçambique, mesmo que se considere importante entre as diferentes condições climáticas.

Apesar da limitação da escala de tempo na observação da precipitação pluviométrica, as características geomorfológicas das paleodunas sugerem sua estrita ligação com a dinâmica das condições paleoclimáticas do sul da África (Partridge, 1997; Tyson, 1999; Tyson e Partridge, 2000; Holmgrenet al 2003, Partridgeet al., 1999, Scott e Lee-Thorp, 2004). Esses trabalhos evidenciaram que a precipitação relativamente alta foi consequência do aumento da temperatura de $1^{\circ} \mathrm{C}$ de $6^{\circ} \mathrm{C}$ a $7^{\circ} \mathrm{C}$ entre 7.500 anos A.P a 5.100 anos A.P. Acredita-se que nesse período, a precipitação anual aumentou até cerca de $10 \%$ acima do presente, diminuindo a atividade eólica nas paleodunas que por sua vez propiciou a colonização por vegetação.

\section{Considerações finais}

A formação do presente complexo sistema lagunabarreira alongado, paralelo ao litoral, composto por paleodunas e dunas holocênicas transgressivas é resultado do suprimento de sedimentos, a existência de espaço de acomodação, a variação das condições climáticas e as mudanças relativas do nível do mar que ocorreram desde 7000 anos A.P na costa de Moçambique. Foram distinguidas quatro fases evolutivas relacionadas às tendências do nível do mar, incluindo: a) a formação de paleodunas interiores e fixas de retaguarda; b) a geração de sistemas lacustre - lagunares paralelos a linha de costa; c) a geração de campos de dunas transgressivos parabólicas, coppice e barcanas e; d) a formação de planícies de deflação e praias atuais.

A taxa de transporte eólico médio foi estimada em $1,4 \mathrm{~kg} / \mathrm{m} / \mathrm{s}$, com maiores contribuições provenientes dos quadrantes SW, SSW, S e SSE. A taxa de transporte eólico anual variou entre $130 \mathrm{~kg} / \mathrm{m} / \mathrm{ano}$ e $501 \mathrm{~kg} / \mathrm{m} / \mathrm{ano}$, que acarreta um assoreamento intenso dos sistemas lacustre - lagunares e desligamento de canais de ligação com o mar numa taxa média de $23 \mathrm{~m} / \mathrm{ano}$. O índice de mobilidade eólico estimado entre 50 e 200 associado a precipitação pluviométrica de até $1600 \mathrm{~mm} / \mathrm{ano}$ contribuíram no desenvolvimento da vegetação de cerca de $70 \%$ sobre as dunas transgressivas. A vegetação sugere um bloqueio significativo da atividade eólica sobre o sistema laguna - barreira de Bilene, costa sul de Moçambique.

Baseando-se nos resultados obtidos e as análises apresentadas, revelou-se que a atuação persistente dos fatores climáticos e sucessivas variações do nível relativo do mar durante o Holoceno, associados ao alto suprimento de sedimentos definiram o campo de dunas transgressivos associados a um sistema laguna-barreira da costa sul de Moçambique.

\section{Agradecimentos}

Agradecemos a CAPES pela bolsa de Doutorado desde 2015. Endereçamos nossos agradecimentos a Universidade Eduardo Mondlane de Moçambique pelo complemento da bolsa. Agradecemos ao senhor Dionísio Uele pelos dados meteorológicos desde 1960 a 2012.A senhora Sheila Filomena Almerindo Machava, estudante da Universidade Eduardo Mondlane, é agradecida pelo duro e incansável apoio prestado nas atividades de campo em 2016 e 2017.

\section{Referências Bibliográficas}

AAGARD,T.; ORFORD,J.; MURRAY,A.S. Environmental controls on coastal dune formation; Skallingen Spit,Denmark. Geomorphology. Vol.83, 29-47,2007doi:10.1016/j. geomorph.2006.06.007

ANTHONSEN, K. L.; CLEMMENSEN, L. B.; JENSEN, J. H. Evolution of a dune from crescentic to parabolic form in response 
to short-term climatic changes: RSbjerg Mile, SkagenOdde, Denmark.Geomorphology. Vol.17 (1996) 63-77, 1995

ARGAMAN, E.,SINGER; A.,TSOAR,H. Erodibility of some crust forming soils/sediments from the Southern Aral Sea Basin as determined in a wind tunnel. Earth Surf. Proc. Land. Vol.31,47-63,2006.

ARMitAGE, S.J.; BOThA, G. A.; DUller, G. A. T.; WINTLE, A. G.; REBÊLO, L. P., MOMAD, F. J.The formation and evolution of the barrier islands of Inhaca and Bazaruto, Mozambique. Geomorphology. Vol.82 (2006) 295-308, 2006.

ASH, J. E.; WASSON, R. J.Vegetation and sand mobility in the Australian desert dunefield.Z. Geomorphol. Vol.45,7-25,1983.

ASHKENAZY, Y.; YIZHAQ,Y.; TSOAR, H. Sand dune mobility under climate change in the Kalahari and Australian deserts. J. Clim. Change 112, 901-923,2012.

BENALLACK, K., GREEN, A.N., HUMPHRIES, M.S., COOPER, J.A.G., DLADLA, N.N., FINCH, J.M.The stratigraphic evolution of a large back-barrier lagoon system with a non-migrating barrier. Mar. Geol. vol.379, 64-77,2016.

BOTHA,G.A.,BRISTOW,C.S.,PORAT,N.,DULLER,G.A.T. ,ARMITAGE,S.J.,ROBERTS,H.M.,CLARKE,B.M.,KOTA, M.W., SCHOEMAN,P. Evidence for dune reactivation from GPR profiles on the Maputaland coastal plain, South Africa. In: Bristow, C.S.,Jol, H.M. (Eds.), Ground Penetrating Radar in Sediments: Special Publication-Geological Society of London, vol. 211, pp. 29-46,2003.

BOYD, R.; DALRYMPLE, R.; ZAITLIN, B.A. Classification of clastic coastal depositional environments.SedimentaryGeology, vol.80 (1992) 139-150, 1992.

CASTRO, J.W.A. Geomorfologia do sistema sedimentar eólico de Paracuru-Ceará. Tese de Doutoramento em Geomorfologia, Programa de Pós Graduação em Geografia, Instituto de Geociências, Universidade Federal do Rio de Janeiro, Brasil, 202p.,2001.

CASTRO, J.W.A., MALTA, J. V., MIGUEL, L.L.A.J., CABRAL, C.L.; PESSAMILIO, A.B., 2017. Chronological reconstruction of eolianites and transversal mobile dunes of northwest coast of Ceará State-Brazil, in the last 3000 calyrs BP. Aeolian Research 28 (2017) 51-57. http://dx.doi.org/10.1016/j.aeolia.2017.07.006 COOPER, J. A. G., PILKEY, O.H. The Barrier Islands of Southern Mozambique.Journal of Coastal Research, SI 36 164-172 (ICS2002 Proceedings), Northern Ireland, ISSN: 0749-0208, 2002.

CURRAY, J.R., EMMEL, F.J, CRAMPTON, P.J.S. Holocene history of a strand plain, lagoonal coast, Nayarit,Mexico. In: A. Ayala-Castanares and F.B. Phleger (Editors), Coastal Lagoons, A Syrup. Univ. Nacional autonoma de Mexico, Ciudad Universitaria, pp. 63-100,1964.

DALRYMPLE, R.W., ZAITLIN, B.A. AND BOYD, R. Estuarine facies models: conceptual basis and stratigraphic implications. J. Sediment. Petrol. (in press), 1992.

DAVIS JR., R. A. \& FITZGERALD, D. M. Beaches and Coasts. Blackwell Publishing. UK. 419p. 2004.

DE LECEA, A.M.; GREEN , A.N. ; STRACHAN, K.L. ; COOPER, J.A.G.; WILES, E.A.Stepped Holocene sea-level rise and its influence on sedimentation in a large marine embayment: Maputo Bay, Mozambique. Estuarine, Coastal and Shelf Science.193 (2017) 25-36, 2017. http://dx.doi.org/10.1016/j. ecss.2017.05.015

DILLENBURG, S.R., HESP, P.A. Coastal barriers-an introduction. In: Dillenburg, S.R.,Hesp, P.A. (Eds.), Geology and Geomorphology of Holocene Coastal Barriers of Brazil. Lecture Notes in Earth Sciences, vol. 107. Springer, pp. 1-15, 2009. ISSN: 0930-0317.

DILLENBURG,S.R.,TOMAZELLI,L.J.,HESP,P.A.,BARBOZA ,E.G.,CLEROT,L.C.P.,SILVA,D.B.Stratigraphy and evolution of a prograded, transgressive dunefield barrier in southern Brazil. JournalofCoastalresearch. SI 39,132-135, 2006.

Direção Nacional de Geologia de Moçambique-DNGM. Carta geológica da região de Bilene. República de Moçambique, 2013.

FERNANDES, G. B., Guilherme Borges. Indicadores Morfológicos para a Origem e Evolução das Barreiras Arenosas Costeiras no Litoral do Estado do Rio de Janeiro. In: VII Simpósio Nacional De Geomorfologia. Minas Gerais, 2008.

FRYBERGER,S.G. Dune forms and wind regime, in: E.D. McKee (Ed.),A Study of Global Sand Seas, in:US.Geol. Surv.,vol.1052,pp.137-169,1979.

GASQUES, J.G., MAGALHES, A.R. Climatic anomalies and their impact in Brazil during the 1982-83 ENSO event. In: Glantz, M., Katz, R., Krenz, M. (Eds.), The Societal Impacts Associated with the 1982-83 Worldwide Climate Anomalies. National Centre for Atmospheric Research, Boulder, pp. 30-36, 1987.

GOMES, M., HUMPHRIES, M.S., KIRSTEN, K.L., GREEN, A.N., FINCH, J.M., DE LECEA, A.M. Diatom-inferred hydrological changes and Holocene geomorphic transitioning of Africa's largest estuarine system, Lake St Lucia, Estuarine, 
Coastal and Shelf Science, $x, p . x x-x x$., 2017doi: 10.1016/ j.ecss.2017.03.030.

HALO,I., BACKEBERG; B., PENVEN,P; ANSORGE,I.; REASON, C.; ULLGREN, J. Eddy properties in the Mozambique Channel: A comparison between observations and two numerical ocean circulation models, Deep Sea Res.,Part II,2014. doi: 10.1016/j.dsr2.2013.10.015, in press.

HASTENRATH, S.Circulation and teleconnection mechanisms of Northeast Brazil droughts. Progress in Oceanography, vol.70, 407-415, 2006.

HESP, P. A., DAVIDSON-ARNOTT, R., WALKER, I.; OLLERHEAD, J. Flow dynamics over a foredune at Prince Edward Island Canada. Geomorphology, vol.65, 71-84, 2005.

HESP, P.A. Conceptual models of the evolution of transgressive dune field systems. Geomorphology. Vol.199 (2013) 138-149, 2013.

HOBDAY, D.K. Late Quaternary sedimentary history of Inhaca Island, Mozambique. Transactions of the Geological Society of South Africa. Vol.80,183-191,1977.

HOLMGREN,K.; LEE-THORP,J.A.; COOPER,G.R.J.; LUNDBLAD,K.; PARTRIDGE,T.C.; SCOTT,L. Persistent millennial - scale climatic variability over the past 25,000 years in Southern Africa. Quaternary Science Reviews. Vol.22, 2311-2326, 2003.

HUMPHRIES, M.S., GREEN, A.N. FINCH, J.M. Evidence of El Niño driven desiccation cycles in a shallow estuarine lake: The evolution and fate of Africa's largest estuarine system, Lake St Lucia. Global andPlanetaryChange. Vol.147 (2016) 97-105;2016.

Instituto Nacional de Hidrografia de Navegação (INAHINA) de Moçambique. Tabela de marés de 2015. 2015.

JARITZ,W.,RÜDER,J.,SCHLENKER,B. Das Quartärim Küstengebiet von Moçambique undseine Schwermineralführung. Geologisches Jahrbuch, vol. B26 ,pp.3-93,1977..

KILIBARDA, Z., SHILLINGLAW, C. A 70 year history of coastal dune migration and beach erosion along the southern shore of Lake Michigan. Aeolian Research.17 (2015) 263273,2014. doi.org/10.1016/j.aeolia.2014.09.002

KINAST, S.;MERON,E., YIZHAQ,H.,ASHKENAZY,Y. Biogenic crust dynamics on sand dunes.Phys. Rev. E 87, 020701(R), 2013.

KUMAR,P.S., PILLAI,G.N, MANJUSHA,U.. El Nino Southern Oscillation (ENSO) impact on tuna fisheries in Indian Ocean.
Springer Open Journal. Springer Plus,vol.2014,3:591.,2014 http://www.springerplus.com/content/3/1/591

LANCASTER,N..Development of linear dunes in the southwestern Kalahari, southern Africa. Journal of Arid Environments. vol.14, 23-244,1988.

LANGA,J.V.Q.Problemas na zona costeira de Moçambique com ênfase para a costa de Maputo. Universidade Eduardo Mondlane, Moçambique.Revista de Gestão Costeira Integrada. vol. 7(1):33-44,2007.

LetTAU,H., LetTAU,H.H. Experimental and micrometeorological field studies of dune migration. IES Report 101. In: Leattau, H.H., Lettau, K. (Eds.). Exploring the World's Driest Climate. University of Wisconsin, Madison, pp. 110-147, 1978.

LEVIN, N.. Climate-driven changes in tropical cyclone intensity shape dune activity on Earth's largest sand island. Geomorphology. Vol.125 (2011) 239-252, 2010. doi:10.1016/j. geomorph.2010.09.021

LIU,L.Y.,SKIDMORE,E.,HASI,E., WAGNER,L., TATARKO, J. Dune sand transport as influenced by wind directions, speed and frequencies in the Ordos Plateau, China. Geomorphology. Vol.67, 283-297, 2005.

MAIA, L.P., FREIRE, G. S. S., LACERDA, L. D. Accelerated dune migration and aeolian transport during El Nino events along the NE Brazilian coast. Journal of Coastal Research. Vol.21, 1121-1126, 2005.

MARTINHO, C. T., DILLENBURG, S., R., HESP, P. A. 2008. Mid to late Holocene evolution of transgressive dune fields from Rio Grande do Sul coast, southern Brazil. Marine Geology 256 (2008) 49-64.doi:10.1016/j.margeo.2008.09.006

MAUD,R.R.,BOTHA,G. A. Deposits of the southeastern and southern coasts. In: Partridge, T.C., Maud, R.R.(Eds.).The Cenozoic of Southern Africa: Oxford Monographs on Geology and Geophysics, vol. 40, pp. 19-32, , 2000.

MCKENNA-NEUMAN, C.; MAXWELL,C.; BOULTON,J. Wind transport of sand surfaces crusted with photoautotrophic microorganisms. Catena. vol.27, 229-247, 1996.

MiguEL, L.L.A. J. CASTRO, J.W.A.; NEHAMA, F. P. J. Tidal impact on suspended sediments in the Macuse estuary in Mozambique. Regional Studies in Marine Science 16 (2017) 1-14. DOI: http://dx.doi.org/10.1016/j.rsma.2017.07.002

MIOT da SILVA, G., HESP, P.A. Coastline orientation, aeolian sediment transport and foredune and dunefield dynamics of Moçambique Beach, Southern Brazil. Geomorphology 120 (2010) 258-278. 2010. doi:10.1016/j.geomorph.2010.03.039 
MOORE,A.E.,COTTERILL,F.P.D.,MAIN, M.P.L., WILLIAMS, H.B. The Zambezi River. In: Gupta, A. (Ed.), Large Rivers: Geomorphology and Management.2008.

NORSTROM,E.,RISBERG,J.,GRONDAHL,H.,HOLMGREN, K.,SNOWBALL,I.,MUGABE,J.A.,SITOE,A.R. Coastal paleoenvironment and sea level change at Macassa Bay, southern Mozambique, since c 6600 cal BP. Quaternary Internacional. vol. 260 (2012)153-163, 2011.

PARTRIDGE,T.C. Cainozoic environmental change in southern Africa, with special emphasis on the last 200000 years. Progress in Physical Geography,pp.213-222, 1997.

PARTRIDGE,T.C.,SCOTT,L.,HAMILTON,J.E.Synthetic reconstructions of southern African environments during the Last Glacial Maximum(21-18 kyr) and the Holocene Altithermal (8-6 kyr).Quaternary International.vol.1 5758, 207-214, 1999

Perry,C.T., 2004.Structure and development of detrital reef deposits in turbid nearshore environments, Inhaca Island, Mozambique. Marine Geology 214 (2005) 143-161

PYE, K. Coastal dunes. Progress in Physical Geography. 1983 (7): 531.DOI:10.1177/030913338300700403

PYE, K. Late Quaternary development of coastal parabolic megadune complexes in northeastern Australia. In Aeolian Sediments: Ancient and Modern, Pye,K, Lancaster,N (eds). Special Publication 16. International Association of Sedimentologists: Oxford; 23-44,1993.

PYE, K. Morpholgical development of coastal dunes in a humid tropical environment, Cape Bedford and Cape Flattery, North Queensland, GeografiskaAnnaler. Series A. Physical Geography vol.64 (1982) 213-227,1982.

RAMSAY, P. J. 9000 years of sea level change along the southern african coastline. Joint Geological Survey, Marine Geoscience Unit, University of Natal, Durban 4001 South Africa. Quaternary International, Vol. 31, pp. 71-75, 1995. doi-1040-6182(95)00040-2

RAMSAY,P.J.,COOPER,J.A.G. Late Quaternary sea level changes in Southern Africa.Quaternary Research. Vol.57, 82-90, 2002.

REINSON, G. E., 1992. in Facies Models: Response to Sea Level Change, eds Walker R. G., James N. P.(Geological Association of Canada, St John's) Transgressive barrier island and estuarine systems, 179-194.

ROY, P.S., COWELL, P. J., FERLAND, M.A., THOM, B. G., 1994: Wave-dominated coasts. In: Coastal Evolution: Late Quaternary Shoreline Morphodynamics [Carter, R.W.G. and
C.D. Woodroffe (eds.)]. Cambridge University Press, Cambridge, UK, pp. 121-186

RUST, I. C. Coastal dunes as indicators of environmental change.Suid-AfrikaanseTydskrifvir Weternskap.vol.86:299302,1990 .

SAUERMANN, G., ANDRADE Jr., J. S., MAIA, L. P., COSTA, U.M.S., ARAUJO, A.D. , HERRMANN, H. J. Wind velocity and sand transport on a barchan dune. Geomorphology 54 (2003) 245 - 255. 2003. doi:10.1016/S0169-555X(02)00359-8 SCOTT,L.,LEE-THORP,J.A. Holocene climate trends and rhythms in southern Africa.In:Battarbee, R.W.,Gasse,F.,Stick ley,C.E.(Eds.),Past Climate Variability Through Europe and Africa. Springer, Dodrecht, The Netherlands, pp. 69-95, 2004.

SILVA, G. M.,HESP,P.,PEIXOTO,J.,DILLENBURG,S.R.Fored une vegetation patterns and alongshore environmental gradients: Moçambique Beach, Santa Catarina Island, Brazil. Earth Surf. Process. Landforms. Vol.33,1557-1573 , 2008.doi:10.1002/ esp.633

SOUZA, C. R. G. et al. Restinga: Conceitos e Empregos do Termo no Brasil e Implicações na Legislação Ambiental. São Paulo: Secretaria de Estado do Meio Ambiente, Instituto Geológico, 2008.

TASKJELlE, T., BARTHEL, K., CHRISTENSEN, K. H., FURACA, N., GAMMELSRØD, T., NHARRELUGA, B. Modelling alongshore flow in a semi-enclosed lagoon strongly forced by tides and waves. Estuarine, Coastal and Shelf Science 149 (2014) 294- 301. 2014. http://dx.doi.org/10.1016/j. ecss.2014.09.008

THOMAS, D.S.G.,WIGGS,G.F.S. Aeolian system responses to global change: challenges of scale, process and temporal integration. Earth Surf. Proc. Land. Vol.33,pp.1396-1418, 2008.

TSOAR, H. Sand dunes mobility and stability in relation to climate. Department of Geography and Environmental Development, Ben-Gurion University of the Negev, Beer Sheva 84105, Israel. PhysicaA.vol. 357(2005).pp 50-56, 2005.

TSOAR, H., 2013. Critical environments: sand dunes and climate change. In: Treatise on Geomorphology. In: Shroder, John, F., Lancaster, N., Sherman, D. J., Baas, A.C.W.(Eds.). Aeolian Geomorphology, Academic Press, San Diego, vol. 11. pp. 414-427.

TYSON,P.D. Atmospheric circulation changes and paleoclimates of southern Africa. South African Journal of Science.vol. 95,pp-194-201,1999. 
TYSON,P.D.,PARTRIDGE,T.C.Evolution of Cenozoic Climates. In: Partridge, T.C., Maud, R.R.(Eds.), The Cenozoic of Southern Africa. Oxford Monographs on Geology, vol. 40 (23), pp-371-387, , 2000.

US Geological Survey. Earth Explorer Project. Accessed through: $<$ http:// earthexplorer.usgs.gov/>.

VÆRET,L.,LEIJNSE,A.,CUAMBA,F.,HALDORSEN, S. Holocene dynamics of the salt-fresh groundwater interface under a sand island, Inhaca, Mozambique. Quaternary International xxx (2011) pp.1-9, 2011. doi:10.1016/j.quaint.2011.11.020.
WIGGS,G.F.S.,ATHERTON, R.J., BAIRD,A.J.Threshol ds of aeolian sand transport: Establishing suitable values. Sedimentology. Vol.51, 95-108, 2004.

YIZHAQ,H.,ASHKENAZYA,Y., TSOAR,H.Sand dune dynamics and climate change: A modelling approach. J. Geophys. Res.,114, 2008. F01023doi:10.1029/2008JF001138.

YIZHAQ,H.,ASHKENAZYA, Y.,LEVIN,N., TSOAR,H. Spatiotemporal model for the progression of transgressive dunes. Physica A. vol. 392 (2013),pp-4502-4515, 2013. 